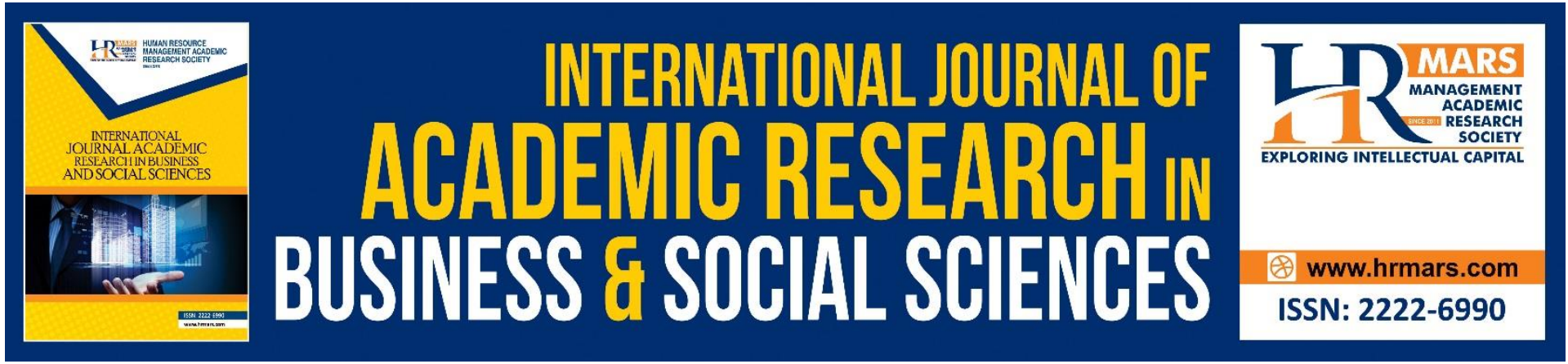

\title{
Does Domestic Violence in Malaysia is Increasing During The Pandemic? Factors and Policy-Related
}

Shadiya Mohamed S. Baqutayan, Mohammad Ariff Abu Hassan, Asrida Binti Asim @ Hashim, Siti Runiza Mohd Zaini, Saiyidah Mohd Salleh

To Link this Article: http://dx.doi.org/10.6007/IJARBSS/v11-i8/10747

DOI:10.6007/IJARBSS/v11-i8/10747

Received: 20 June 2021, Revised: 24 July 2021, Accepted: 02 July 2021

Published Online: 17 August 2021

In-Text Citation: (Baqutayan et al., 2021)

To Cite this Article: Baqutayan, S. M. S., Hassan, M. A. A., Hashim, A. B. A. @, Zaini, S. R. M., \& Salleh, S. M. (2021). Does Domestic Violence in Malaysia is Increasing During The Pandemic? Factors and PolicyRelated. International Journal of Academic Research in Business and Social Sciences, 11(8), 579-592.

Copyright: (c) 2021 The Author(s)

Published by Human Resource Management Academic Research Society (www.hrmars.com)

This article is published under the Creative Commons Attribution (CC BY 4.0) license. Anyone may reproduce, distribute, translate and create derivative works of this article (for both commercial and non-commercial purposes), subject to full attribution to the original publication and authors. The full terms of this license may be seen at: http://creativecommons.org/licences/by/4.0/legalcode

Vol. 11, No. 8, 2021, Pg. 579 - 592

http://hrmars.com/index.php/pages/detail/IJARBSS

JOURNAL HOMEPAGE

Full Terms \& Conditions of access and use can be found at http://hrmars.com/index.php/pages/detail/publication-ethics 


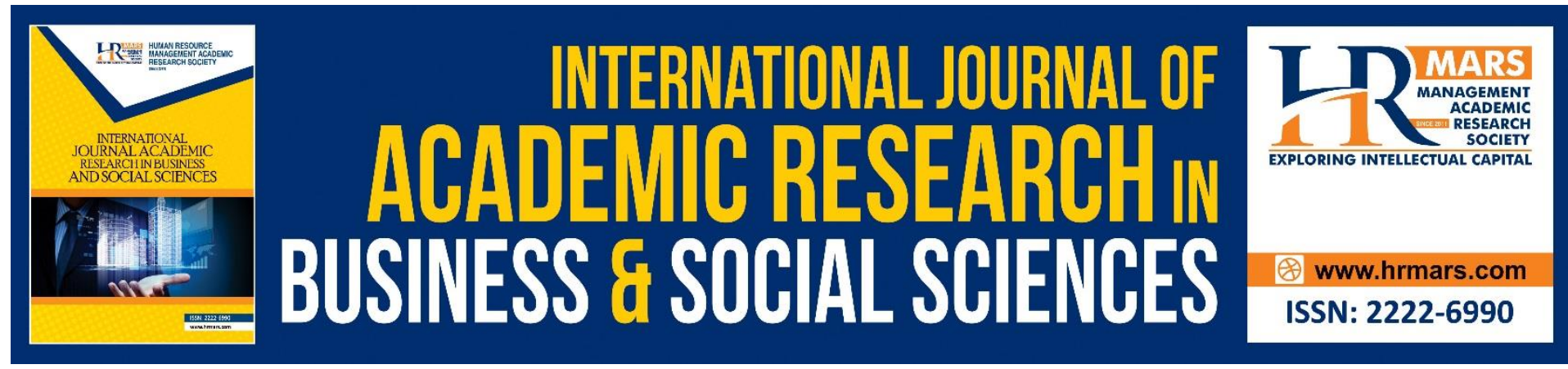

\title{
Does Domestic Violence in Malaysia is Increasing During The Pandemic? Factors and Policy-Related
}

\author{
Shadiya Mohamed S. Baqutayan, Mohammad Ariff Abu \\ Hassan, Asrida Binti Asim @ Hashim, Siti Runiza Mohd Zaini, \\ Saiyidah Mohd Salleh \\ Razak Faculty of Technology and Informatics, University Technology Malaysia (UTM) UTM, \\ Jalan Sultan Yahya Petra, Malaysia \\ Email: Shadiya.kl@utm.my
}

\begin{abstract}
During Covid-19, Malaysia has announced the Movement Control Order (MCO) in which was started on March 18, 2020, to curb the spread of coronavirus amongst Malaysian. This tested people's emotions, feelings, and the way they act. It also has tested their patient, resilience, and their ability to be kind and caring. Thus the study focus on the factors contributing to domestic violence in Malaysia. The objective of this paper is to examine the level of awareness on domestic violence during the $\mathrm{MCO}$ and suggest ways to prevent or reduce domestic violence in Malaysia via Government policies and interventions as well as enforcement measures related to acts and laws. The study used a hybrid method of a random online survey as well as Malaysia's policy review to gauge factors that lead to Domestic Violence in Malaysia during the Covid -19 pandemic. The results indicated that Stability in economic status, educational level, and upbringing in an urban area enable to curb domestic violence from occurring despite facing challenging situations dealing with pandemic Covid -19. As domestic violence deemed to be taboo to be discussed in Malaysian community due to its culture, the study concludes that citizen in big cities is well aware on the avenue and laws that designed by the relevant authority to protect people. Citizens are also aware that the pandemic triggered more incidents to happened and they have the knowledge on support systems available in the country. This is essential so that appropriate recommendations on the next course of action be proposed to the stakeholders on how to achieve zero domestic violence in Malaysia
\end{abstract}

Keyword: Domestic Violence, Factors of Domestic Violence, Policy

\section{Introduction}

The issue of domestic violence is not something new in Malaysia. Recently, reports of incidents of domestic violence are increasing during the pandemic. A total case of 2,287 was reported in 2020, particularly high during the implementation of the movement control order (KPWKM, 2020). According to the Women's Centre for Change (WCC), the rise of domestic violence during the pandemic was due to economic, social, and psychological pressure on individuals, families as well as communities. As part of the Sustainable Development Goals 
(SDG), under Goal 1.a.2: No Poverty on "Proportion of total government spending on essential services (education, health, and social protection)" and Goal 5.2: Gender Equality, the United Nations (UN) has targeted to "Eliminate all forms of violence against all women and girls in the public and private spheres, including trafficking and sexual and other types of exploitation".

Domestic Violence Act define domestic violence as means the commission of one or more of these acts which are willfully or knowingly placing, or attempting to place, the victim in fear of physical injury; causing physical injury to the victim by such act which is known or ought to have been known would result in physical injury; compelling the victim by force or threat to engage in any conduct or act, sexual or otherwise, from which the victim has a right to abstain; confining or detaining the victim against the victim's will; causing mischief or destruction or damage to property with intent to cause or knowing that it is likely to cause distress or annoyance to the victim; dishonestly misappropriating the victim's property which causes the victim to suffer distress due to financial loss; and threatening the victim with intent to cause the victim to fear for his or her safety or the safety of his or her property, to fear for the safety of a third person, or to suffer distress; communicating with the victim, or communicating about the victim to a third person, with intent to insult the modesty of the victim through any means, electronic or otherwise; causing psychological abuse which includes emotional injury to the victim; causing the victim to suffer delusions by using any intoxicating substance or any other substance without the victim's consent or if the consent is given, the consent was unlawfully obtained; or in the case where the victim is a child, causing the victim to suffer delusions by using any intoxicating substance or any other substance. In Malaysia, the Malaysian Parliament passed The Domestic Violence Act (DVA) in 1994 and implemented it in June 1996. Under the DVA, domestic violence is not defined as a specific crime punishable by new penalties; however, it is attached to the Panel Code under definitions and procedures for hurt, criminal force, and assault (Halimah \& Hariharan, 2011). The Ministry of Women, Family, and Community Development is in charge of managing the issues of domestic violence in Malaysia. Through the National Women Policy and Women's Development Action Plan, 2009 has highlighted six (6) objectives to address the issues of violence against women, which include reducing the case of domestic violence against women and educating and raising awareness to eliminate all forms of violence against women. For the record, there is a nongovernment organization (NGO) that support women's right such as Women Centre for Change (WCC), All Women's Action Society (AWAM), Women's Aid Organisation (WAO), Pertubuhan Kesedaran Wanita Kedah (PKWK), Sarawak Women for Women Society (SWWS) and the Sabah Women Action Resource Group (SAWO) (Abdul Ghani, 2014).

\section{Methodology}

The purpose of this study is to investigate the issue of domestic violence in Malaysia. A survey was conducted to measure domestic violence through possible factors, which are psychological, economic, and social factors. The questionnaire consists of three parts, the first part was on demographic information, the second part is on the factor associated with domestic violence (psychological, economic, and social factors), and the third part was an open-ended question asking the respondents on their view on domestic violence in Malaysia. On psychological factors, the act of violence including the treatment of partners to each other, the right to make decisions equally, humiliating partner, physical abuse as well as any act of abusive intimate relationship. Economic factors examine the decisions on money matters, financial decisions, a partner willing to work for the family, debt management as well as 
monthly commitments. Finally, on social factors examine on the level of awareness of the society on domestic violence, training, and leaflets available on domestic violence, lower socio-economic group leads to domestic violence and the need for guidelines on domestic violence. Apart from the respondents, secondary data from various government agencies locally and internationally, non-government organizations available domestic violence issues. Apart from an online survey, the policy study was done based on the policy aligned by the Ministry of Women, Family and Community Development (KPWKM). In 2014, the Ministry started to adhere to the Domestic Violence Act 1994, Act 521. The study was also done based on secondary data from the Women's Aid Organization (WAO) website. The WAO is a NonGovernment Organization (NGO) that provides free services including counseling to domestic violence victims specifically women.

Moreover, the items in the second part of this measurement measured based on the 5-Likertscale ranging from (1)

"Strongly disagree" to (5) "strongly agree". The detail as followed:

i. Strongly Disagree : Respondent strongly disagree with the statement

ii. Moderately Disagree : Respondent moderately disagree with the statement

iii. Slightly Disagree : $\quad$ Respondent slightly disagree with the statement

iv. Moderately Agree : Respondent moderately agree with the statement

v. Strongly agree : Respondent strongly agree with the statement

About 300 respondents were randomly selected from government and private industries and yielded a response rate of 202 (67.3\% response rate). Data were analyzed using SPSS and AMOS to achieve the objectives; thus, descriptive statistics were used to analyze the study variables. Moreover, Correlational Analysis and Structural Equation Modeling (SEM) are used to examine the research hypotheses.

\section{Results and Findings}

\section{Participants' Background}

Table 1 shows the distribution of the main characteristics of the participants or/and respondents' background according to their gender, age, race, marital status, educational level, employment, etc. 
Table 1 below shows the demographic profile of the respondents for this questionnaire

\begin{tabular}{|c|c|c|c|}
\hline Demographic Profile & & Frequency & Percentage \% \\
\hline \multirow[t]{6}{*}{ Age } & $20-30$ & 40 & 19.8 \\
\hline & $31-40$ & 66 & 32.67 \\
\hline & $41-50$ & 58 & 28.71 \\
\hline & $51-60$ & 28 & 13.86 \\
\hline & Above 60 & 9 & 4.46 \\
\hline & Other & 1 & 0.50 \\
\hline \multirow[t]{2}{*}{ Gender } & Man & 78 & 38.61 \\
\hline & Woman & 124 & 61.39 \\
\hline \multirow[t]{3}{*}{ Marital Status } & Single & 43 & 21.29 \\
\hline & Married & 152 & 75.25 \\
\hline & Divorce & 7 & 3.47 \\
\hline \multirow[t]{4}{*}{ Race } & Malay & 183 & 90.59 \\
\hline & Chinese & 7 & 3.47 \\
\hline & Indian & 6 & 2.97 \\
\hline & Others & 6 & 2.97 \\
\hline \multirow[t]{5}{*}{ Level of Education } & $\begin{array}{l}\text { No formal } \\
\text { education }\end{array}$ & 1 & 2.97 \\
\hline & Primary & 0 & 0.00 \\
\hline & Secondary & 27 & 13.37 \\
\hline & University & 163 & 80.69 \\
\hline & Others & 11 & 5.45 \\
\hline \multirow[t]{7}{*}{ Years of Marriage } & Less than 1 year & 30 & 16.22 \\
\hline & 2-3 years & 10 & 5.41 \\
\hline & $4-6$ years & 13 & 7.03 \\
\hline & $6-10$ years & 34 & 18.38 \\
\hline & $10-15$ years & 38 & 20.54 \\
\hline & $\begin{array}{c}\text { More than } 16 \\
\text { years }\end{array}$ & 60 & 32.43 \\
\hline & Missing Value & 17 & 8.4 \\
\hline \multirow[t]{7}{*}{ Number of kids } & None & 51 & 26.02 \\
\hline & 1 & 30 & 15.31 \\
\hline & $2-3$ & 78 & 39.8 \\
\hline & 4-5 & 34 & 17.35 \\
\hline & More than 6 & 3 & 1.53 \\
\hline & Adopted & 0 & 0.00 \\
\hline & Missing value & 6 & 2.97 \\
\hline TOTAL & & 202 & 100 \\
\hline
\end{tabular}

Based on the respondents' demographic information, the descriptive analysis was conducted (Table 1 ) and the results indicated that $61.39 \%$ of respondents were female and $38.61 \%$ Were male gender, the marital status of respondents was single $(21.29 \%)$, married $(75.25 \%)$, and divorce (3.47\%). In addition, their age was between 20-30 (19.8\%), 31-40 (32.67\%), 41-50 (28.71\%), 51-60 (13.86\%), and above 60 (4.46\%). Of the 163 (80.69\%) of the respondents has a university degree/master or higher than that. $46(76.67 \%)$ respondents who have been married for more than 16 years have a university qualification. 


\section{Factors Affecting Domestic Violence}

\section{A. Psychological Factor}

The psychological factor in relation to domestic violence was measured and the result was highlighted in the following diagram.

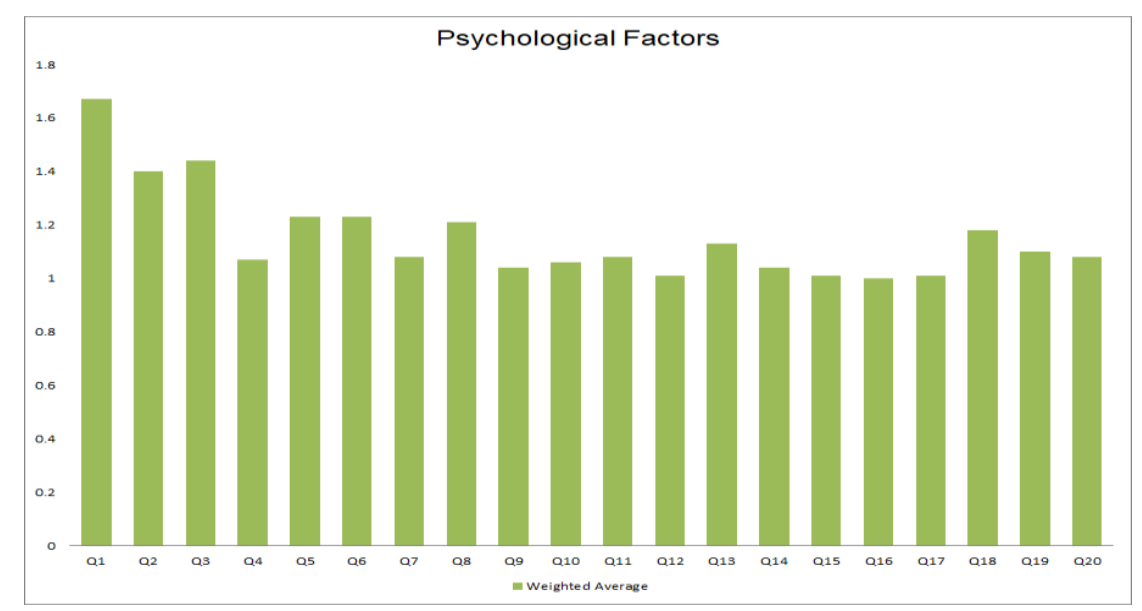

Figure 1: Psychological Factor In Relation To Domestic Violence

Thus, on the psychological factors of domestics' violence that solicited with any uncivil behavior that they have experienced last year, more than half of the respondents' answers they never experienced any physical abuse during the time. Only $3(1.83 \%)$ respondents felt their partner often gets irritated/suspicious/angry if they talked to other women or men. The other significant association is that $3(1.83 \%)$ of the respondents felt that their partners treated them like a servant. The data also found that $78(38.9 \%)$ of the respondents have $2-$ 3 kids or more. The survey also found that families with 2-3 kids or more never been unfaithful and never had any extramarital relationships whereby $68(98.55 \%)$ agree that their partner never did this. Only $1(1.75 \%)$ respondent who has been married for more than 16 years admit to being threatened by their partner. The data also showed that 2 (1.22\%) respondents, one is a male respondent and another one is a female respondent were not allowed to partake in the important decision-making. Figure 1 shows the weighted average of psychological factors responded in the surveys

\section{B. Economic Factor}

Apart from psychological factors, respondents were also asked to give their views on the financial-related matter. A set of questions were given to the respondents, and the result as below: 


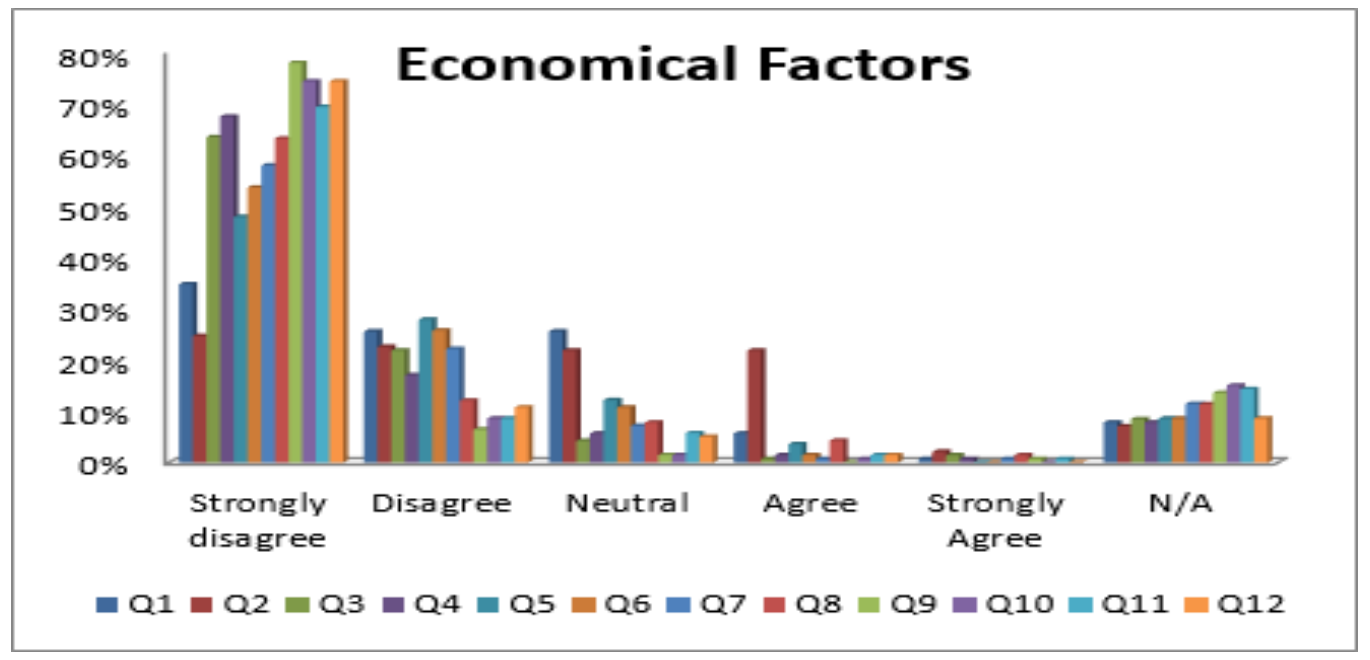

Figure 2: Economic Factor In Relation To Domestic Violence.

The data shows that in financial related matters, 142 respondents have answered these questionnaires. 1 (1.67\%) male respondents strongly agree that their partner decided on how he can spend his money. While $3(5 \%)$ of male respondents answered that their partner demanded to know where the money was spent. 2 (3.3\%) of them also strongly agree that their partner took their earnings or savings without their will. On the other hand, $2(2.44 \%)$ of female respondents admitted that their partner refused to get a job. 94 (77.69\%) of the respondents who have a university level of education strongly disagree that their partner gambling with their shared money. Based on the same association, only 2 (1.65\%) agreed their partner has spent their money towards unnecessary things than paying monthly commitments. The analysis also showed that only $3(5.77 \%)$ of them who have been married for more than 16 years keep financial information from them while 25 (48.08) disagree on this. Only 1 (1.92\%) couple of the same association makes an important financial decision without discussing it first. The lesser resources a woman has, the less power she has and the more she is entrapped in a marriage, and the more she suffers at the hands of her husband (Randawar \& jayabalan, 2018). In the analysis, only 14 (17.07\%) women agree that their partner demands to know where her money was spent. It indicated that women are free to spend their money without the concerns of her partner.

\section{C. social factor}

Apart from psychological and economic factors, respondents were also asked to give their views on the social factor. A set of questions were given to the respondents, and the result as below: 


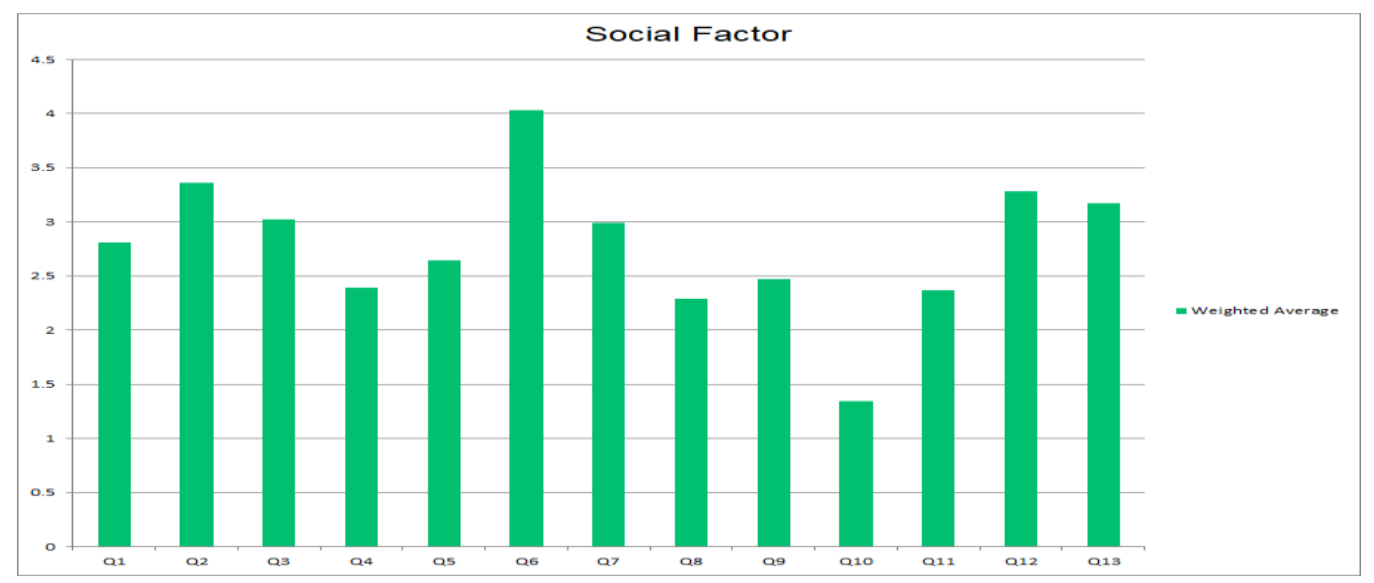

Figure 3: Social Factor In Relation To Domestic Violence.

When it comes to measuring their awareness level, the data showed only $122(60.39 \%)$ respondents answered the questionnaires. The data showed that $76(62.3 \%)$ sometimes follow reports on domestic violence in the media. When further analyzed, 59 (56.19\%) respondents from the university level of education sometimes think that domestic violence is more common in the ethnic minority in Malaysia. A large percentage of respondents from the same group which is 55 (55\%) sometimes heard about Malaysia's policy on domestic violence, while 17 (17\%) never heard of any. 47 (38.84\%) of respondents think that domestic violence is a serious issue in society. Having identified, as the majority of respondents that answered the questionnaires were Malay, 43 (42.16\%) of respondents from this group sometimes feel uncomfortable when asked about domestic violence. A large percentage of respondents 86 (74.78\%) of respondents never went for any training about domestic violence. Out of this, 33 $(67.35 \%)$ are male and $53(80.30 \%)$ are female. The analysis also indicated that $42(37.17 \%)$ respondents never thought about the need for any written guidelines for domestic violence. The data suggest that the level of awareness on the society about domestic violence are still low and training needed to be given to the society to avoid being the victims of domestic violence. As the hybrid method was used in this study, the elaboration on domestic violence in Malaysia will be dissected further in our next discussion topic.

\section{Discussion}

As the study was done randomly online, the responses gathered are mostly from Malaysians who have undergone formal education. The education act is a pillar in setting up the nation to be aware of domestic violence. Apart from building up the student with specific soft skills using formal education received during primary, secondary, and universities. Malaysian at large is exposed to the correct way of dealing with the crisis. The Ministry of Education (MOE) and Ministry of Higher Education (MOHE) have introduced many syllabuses to prepare students with soft skills in crisis management. Indirectly, people who attended formal schools have been trained and established to manage crises wisely. Apart from formal education training for Muslims as an individual was done before any couple embarking on a wedding. This training is one of the procedures that need to be completed by anyone who attempts to get married. One of the topics that being look upon is the management of the family crisis. It is safe to say that, at the very minimum, Muslim couples in Malaysia are aware of the needful and way to conduct themself during a crisis. However, such training is not available to any other religions before their wedding. One has to depend on their upbringing and religious background in tackling issues in marriage. Apart from that, although the pre-training was 
conducted as compulsory, the post-training is not imposed on any couple in Malaysia. Structured training for post-wedding is normally done voluntarily. As marriage is for life, the dynamism of issues faced by the couple are varied throughout their marriage, periodic training of at least every 3 years is recommended for post marriage. This is to help all couples to keep on learning new skills in overcoming issues. Society in general needs to get solid evidence, that with the commitment shown by the country's leaders, the agenda of empowering the economy is an indirect result is centered on the strength of the people in the country as the basic unit of community building.

According to Sharma and Borah (2020), the fundamental reason for domestic violence is a lack of economic well-being. As most of the respondents agreed to the fact that as a couple, to manage the finances well, the responsibility of making sure that finances are a shared responsibility. Each of the spouses needs to ensure that their financial management is done well. Since most respondents are from the working women group, although in principle, any salary generated by the wife belongs to the wife, mutual agreement among the spouse is to discuss the usage of their source of income. It was also found that couples need to avoid bad habits such as using credit cards obsessively, having bad debt, borrowing money from other people without returning it and the highest level of mismanagement is to participate in gambling. As most of the responders are Malays, we can deduce that the responders are mainly Muslim. As a Muslim, one has been learning from the beginning to adopt and adhere to a lifestyle as preached by Prophet Muhammad. Treating the elderly, women and kids is one of the main moral values raised by Islam. Even during the war, the treatment towards older, women and kids being explicitly mentioned by Prophet Muhammad (Jabatan Kemajuan Islam Malaysia, 2008). There are many verses in Alquran, stress the importance of treating your wife and those under your supervision in a rightful way. At every stage of marriage, be it during the initial, while in the marriage as well as facing with divorcing situation, Alquran have aligned the ummah accordingly of the importance of not to astray as a couple. Higher responsibility is granted to man as a leader in the family. One of the most relevant verses on this matter is written as;

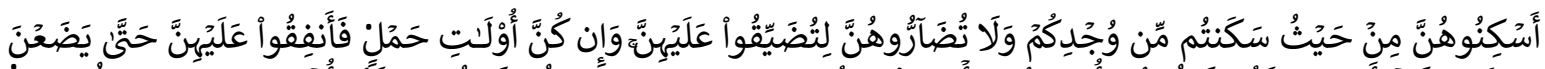

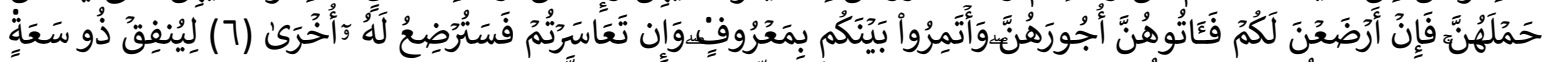

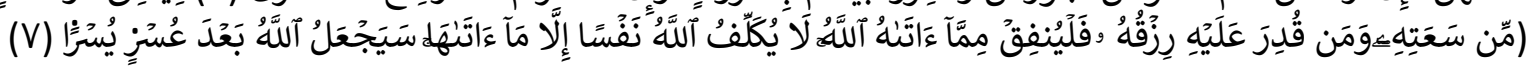

"Lodge them [in a section] of where you dwell out of your means and do not harm them to oppress them. And if they should be pregnant, then spend on them until they give birth. And if they breastfeed for you, then give them their payment and acceptably confer among yourselves; but if you are in discord, then there may breastfeed for the father another woman." "Let a man of wealth spend from his wealth, and he whose provision is restrictedlet him spend from what Allah has given him. Allah does not charge a soul except [according to] what He has given it. Allah will bring about, after hardship, ease." Quran; Al Talaq:6-7

The fact that there two chapters in Al-Quran namely as Surah An-Nisa (which mean woman) as well Al-Talaq (Divorce) meaning that Al-Quran as a living text explicitly mentioned the importance of woman and family matters to the extent of even after a man divorcing a wife, there is certain rules and regulation need to be adhered to by true believer. This is the true testament that shows, family is important in the building of a nation, as such detailed guidance is written to enable Muslims to work within the allowable junction. And as most of 
the respondents are mostly educated women, the study can also conclude that they have a unique way to handle and curb domestic violence from happening. Another angle that can be looked upon is the Malay culture of not exposing to others their internal affairs. The reason is mainly because of shyness as well as to "saving face" of the spouse. This is a unique culture that remained embedded in pure Malay. The "face-value" is important to save than to let others know about their affairs that have options to be controlled accordingly.

People always associated domestic violence with mental health, but before we could relate it two main points must be highlighted on the wrong perception that domestic violence and mental health. First, the majority of people with mental illness are not violent (Fazel et al., 2009). Second, the mental illness itself does not cause any violence to oneself. Domestic violence is strongly related to the person's need to have more power and control towards others. Cases related to domestic violence mostly associated with physical abuse towards the spouse. It shows that one wanted to be in control and to make others fear them. In this study, most of the respondents come from an educated environment and having stable income distribution, thus it is believed the intention to have more power or control against each other does not exist. Though the respondent in this study does not show directly domestic violence is associated with mental health or illness, still, this variable could be among the causes of domestic violence during the pandemic. People are isolated and because of COVID 19 and restrictions of movement has led to depression and anxiety among spouse.

In terms of the respondent's opinion on domestic violence in Malaysia, it is viewed as a serious issue, and actions needed to be taken against those who committed it. Public awareness of domestic violence is also important to avoid or to reduce unreported cases. Lower-income and uneducated persons may lead to domestic violence as well. The respondents also agree that families need to be economically stable to avoid the case of domestic violence. Changes in the financial or sudden loss of income will lead to stress and exasperation will also cause a spike of domestic violence. These situations have been shown to play a big part in the character of the family harmony, especially if the men are the sole providers of the family or a breadwinner husband. In most cases, the women and children will become the victim of the consequences where the husband is abusing them to relish his anger. So, some suggest staying closer to the religion and adhere to their religion's teaching. Some respondents think that abuse is caused by a mentally unstable individual, probably due to stress and mental depression from their childhood. There was a view that domestic violence happened due to the failure of the family institutions started from the house and will have an effect on the society at large. Bad influence from social media also can increase the cases of domestic violence. Lack of enforcement on the abused cases as well as little knowledge on the Act of domestic violence was amongst the opinions given. One interesting opinion given was that the partners who sense some abused in the early marriage should go for counseling, to reduce and manage the misunderstanding among them and to avoid prolonged trauma.

Indeed, Fallahi, Rahpaymaelizehee, \& Kojour, (2015), stated that to enhance the quality of life of women in family and society, the government should make policies that would decrease the violence in society and household field and should more emphasis on providing facilities and services such as the provision of houses to accommodate victims. Based on the Ministry of Economic Affairs, Malaysia (2018) in the Mid Term Review of the $11^{\text {th }}$ Malaysia Plan 20162020, there are issues highlighted whereby domestic violence against women is mainly attributed to poor moral and religious values as well as lack of community support. The government also introduced a joint effort between government agencies and civil societies to educate women and children to be aware of their rights and protection against violence. They 
launched Talian Nur 15999 as a system that works for a 24-hour hotline to help the victim to report any violence cases against them. Furthermore, a better understanding of the available policy framework will encourage the victims to come forward and report the case of abuse to them. Society, the government, as well as the NGOs, need to work together to curb the domestic violence issues in Malaysia

\section{Conclusions}

As domestic violence is deemed taboo in Malaysian culture, in terms of Malaysia's policy perspective, the available facilitation from the Ministry of Women is needed to enable the dissemination of information to the public. In surviving the event of massive prolonged stress like the Covid-19 pandemic; information to give immediate help should be available at fingertips. According to Gulatia \& Kelly (2020), a heightened risk of domestic violence has been associated with infection-reducing measures undertaken by governments during the COVID-19 pandemic. Psychiatric services can play a key role in addressing this issue by addressing certain risk factors for perpetration of domestic violence through assertive identification and management of substance misuse, providing support, advocacy, and treatment services for victims of domestic violence, and finally, multi-agency working to strengthen medical and social responses to domestic violence. Thus, many respondents are aware that authorities are working diligently to curb this matter. The result of the survey is critical to reflect knowledge and awareness among the public, on the method and means of action to do when dealing with domestic violence in Malaysia. Many respondents are also aware that domestic violence in Malaysia is happening and they think some cases are not even reported to the authority. The study also encounters limitations in data collection, due to the Covid -19 pandemic restrictions, the survey is being done as a full virtual survey. Mediums used are the Whatapps application, Instagram, and Twitter. The method is chosen, however, has led to the respondent's gains are within a similar demographic. An effort was done to disseminate the survey via Kisah Rumah Tangga, a public group on Facebook. The channel was chosen to survey due to the nature of the group in conducting open discussion towards any domestic issues related to marriage. With viewers of 1.5 millions and using Bahasa Melayu as a medium, survey's penetration to the group such as this group will enable a more precise study to be done, however, the administrator of the group does not respond to our request and is deemed as are not interested in revealing our surveys online to their viewers. In conclusion, one of the issues faced during the surveys is the openness gained from the respondents towards the surveys. It is recommended that physical surveys such as interviews shall need to be conducted in the future to gain and entice more openness from the respondents. It is also suggested that for the future purpose of gathering input/data, a different targeted and demographic group should be considered for instance to disseminate the survey to the B40 and M20 group to capture more data from different demographics.

\section{Contribution of The Study}

This research contributes in enriching the body of knowledge on domestic violence during the pandemic, it has made contributions to the literature on women's issues in Malaysia, Moreover, the academic implications of the research results have also expanded the body of knowledge through empirical evidence on the measurement of variables involved that the research has developed a translated version of the questionnaire in Malaysian Language, which offers its potential to be utilized for research in the context of Malaysia. Moreover, the high rate of domestic violence justifies the need for effective methods to improve women's 
quality of life. Hence, the outcome of this research will assist policymakers to achieve zero domestic violence in Malaysia. Finally, this research carries values to the Sustainable Development Goals (SDG) in enhancing the policy on women's issues and gender equality.

\section{Acknowledgment}

I would like to express my special thanks to Universiti Teknologi Malaysia (UTM) that has provided me with the opportunity to write on this topic, using Encouragement Research grants (PY/2020/04096). My sincere thank also to my colleagues who have kindly provided me with valuable comments for this article.

\section{Conflict of Interest}

The authors hereby declare that they have no conflict of interests.

\section{Funding}

The author(s) received no financial support for the research, authorship, and/or publication of this article.

\section{References}

Abdul Ghani, M. (2014). Exploring Domestic Violence From The Perspective of Abused Women in Malaysia. A Doctoral Thesis, submitted in partial fulfillment of the requirements for the award of Doctor of Philosophy of Loughborough University. Retrieved 2021, from: https://www.researchgate.net/profile/Mariny-Abdul-

Ghani/publication/334537790_EXPLORING_DOMESTIC_VIOLENCE_EXPERIENCES_FRO M_THE_PERSPECTIVE_OF_ABUSED_WOMEN_IN_MALAYSIA/links/5d30609f92851cf44 08d63ed/EXPLORING-DOMESTIC-VIOLENCE-EXPERIENCES-FROM-THE-PERSPECTIVEOF-ABUSED-WOMEN-IN-MALAYSIA.pdf

Fallahi, B., Rahpaymaelizehee, S., \& Kojour, R. J. (2015). The National Policy of Malaysia toward Violence against Women. Public Policy and Administration Research, 5 (5): 1-5.

Fazel, S., Gulati, G., Linsell, L., Geddes, J. R., \& Grann, M., (2009). Schizophrenia and Violence: Systematic Review and Meta-Analysis. PLoS Medicine, 6 (8): 1-15.

Gulatia, G., \& Kelly, B. D. (2020). Domestic violence against women and the COVID-19 pandemic: What is the role of psychiatry? Int J Law Psychiatry, 71: 101594. doi: 10.1016/j.ijlp.2020.101594

Halimah, A., \& Hariharan, S. (2011). Determinants of Domestic Violence: Evidence from Malaysia. Journal of Family Violence, 26 (6): 459-464.

Jabatan Kemajuan Islam Malaysia. (2008). Memasuki gerbang perkahwinan (2 ed). Jabatan Kemajuan Islam Malaysia (JAKIM), (p. 62-85).

KPWKM. (2020). Kementerian Pembangunan Wanita, Keluarga dan Masyarakat, Malaysia. Retrieved 2021, from: https://www.lawyerment.com/guide/gov/Federal_ Government/Women_Family_and_Community_Development/2158.htm

Ministry of Economic Affairs Malaysia. (2018). Mid Term Review of $11^{\text {th }}$ Malaysia Plan 20162020. New priorities and emphases. Retrieved from:

https://www.talentcorp.com.my/clients/TalentCorp_2016_7A6571AE-D9D0-4175-

B35D-99EC514F2D24/contentms/img/publication/Mid-

Term\%20Review\%20of\%2011th\%20Malaysia\%20Plan.pdf 
Randawar, D. K., \& jayabalan, S. (2018). The Definition of Domestic Violence in Malaysia: A Cross-National Comparison. Akademika journal of southeast Asia social science and Humanities, 88 (3): 77-89.

Sharma, A., \& Borah, S. B. (2020). Covid-19 and Domestic Violence: an Indirect Path to Social and Economic Crisis. Journal of Family Violence 2020. https://doi.org/10.1007/s10896020-00188-8

\section{The Psychological Factors Questionnaire}

\section{Appendix}

Q1 Partner gets irritated/suspicious/ angry if you talked to other men/ women

Q2 Accused you of being unfaithful

Q3 Did not permit to meet/ interact with friends of opposite sex

Q4 Restricted interaction with my family members

Q5 Partner treated me like a servant

Q6 Do not allow me to partake in decision making

Q7 Partner was unfaithful to me and had extra-marital relationships

Q8 Insulted me in front of others

Q9 Threaten to harm me physically

Q10 Slapped me

Q11 Beat me on other body parts

Q12 Twisted my arms / pulled my hair

Q13 Pushed/ shook/threw something at me

Q14 Punched me with fist or some objects

Q15 Kicked/ dragged me

Q16 Choked me or inflicted burns on me

Q17 Attacked me with knife or some other weapon

Q18 Ignored you purposely, by not having sexual intercourse with you for weeks

Q19 Had sexual intercourse with me forcibly, even when I am not interested

Q20 Partner kept away from home for days without informing me / giving me money

\section{The Economic Factors Questionnaire}

Q1 My partner decides on how I could spend my money

Q2 My partner demands to know how money was spent

Q3 My partner took my earnings or savings from me against my will

Q4 Keep me from having access to my bank accounts

Q5 Keep financial information from me

Q6 Make important financial decision without talking with me about it first

Q7 Build up debt like using credit cards or pay bills late

Q8 Refuse to get a job so I had to support my family alone

Q9 Gamble with my money or our shared money

Q10 Borrowing money from my family or friends but not able to pay them back

Q11 Pawn your property or your shared property

Spent the money towards unnecessary things rather than paying monthly

Q12 commitments 


\section{The Social Factors Questionnaire}

Q1 Do you follow reports about domestic's violence in the media?

Q2 Does domestic violence occur more in lower socio-economic groups?

Q3 Does domestic violence more common in ethnic minorities in Malaysia?

Do any leaflets about domestic violence reflect to the specific ethnicity in your

Q4 population?

Q5 Have you ever heard of Malaysia's policy on domestic violence?

Q6 I think domestic violence is a serious issue in the society

Q7 I think domestic violence is a private matter between partners

Q8 I think domestic violence is part of normal life

Q9 I feel uncomfortable asking direct questions about domestic violence

Q10 I went for training about domestic violence

Q11 I see no need for any written guidelines for managing domestic violence I think abused women / men should leave their partner if they do not like being hit,

Q12 whatever the circumstances

I think if a women / man leaves an abusive partner, the abuse by him/her is likely to

Q13 stop

Q14 Other (please specify) 